\title{
The Long-term Impact of International Study: Indonesian Graduate Students in Japan and Their Subsequent Academic Careers in Indonesia
}

\author{
Arikawa Tomoko \\ Center for International Education and Exchange, Osaka University, Japan
}

Copyright $\mathrm{O} 2019$ by authors, all rights reserved. Authors agree that this article remains permanently open access under the terms of the Creative Commons Attribution License 4.0 International License

\begin{abstract}
This paper examines the international-student perspective of the long-term impact of international study. Based on a longitudinal ethnographic study, this paper focuses on the learning by Indonesian graduate students in the Japanese research and teaching koza communities at Japanese higher-education institutions, and it examines the long-term influence of studying in Japan on their subsequent academic careers in Indonesia. It was found that alumni selectively chose to adapt to the teaching and research practices that they had positively valued in their respective koza when settling into their subsequent academic careers in Indonesia. Overall, the former international students that were interviewed gave a positive evaluation of their experiences in Japan and had adapted the Japanese koza methods that they felt would work well in Indonesia. This paper clarifies some of the long-term impacts of international study on international students.
\end{abstract}

Keywords International Students, Long-term Impact, Graduate Study, Japan, Indonesia

\section{Introduction}

This paper examines how international graduates' study influenced the long-term academic careers of international students. Based on a longitudinal ethnographic study of Indonesians who had studied in Japan, this paper explores how individual Indonesians interpreted and used their experiences in regular graduate programs in Japan in their careers as university faculty in Indonesia. It also examines the relationship between the international graduate-student experiences at the micro level and the systems and programs at their respective higher-education institutions, and whether these were influenced by history and current government and international policies.

After an overview of Japanese higher-education internationalization and studies that employed relevant research approaches with regard to international students, the koza teaching and research system at national university corporations in Japan is explained. Lave and Wenger's (1991) concept of "legitimate peripheral participation" "in the sociocultural practices of a community" is used to explain the koza research and teaching system at a Japanese university. After briefly explaining the relevant issues in the context of Indonesian universities, this paper introduces some Indonesian graduate-student cases and examines those students' koza experiences in Japan and their ideas on teaching and research as university faculty after returning to Indonesia, from which the long-term impact of international study is assessed.

\section{Context of Japanese Higher Education}

\subsection{History of Japanese Higher Education and Language}

Japanese higher education has been influenced by western systems since the late $19^{\text {th }}$ century (e.g., Altbach, 2016/1989 ${ }^{1}$, p. 209; Clark, 1983, p. 230; Clark, 1995, pp.159-185). In the late $19^{\text {th }}$ century, Japan adopted a German chair system (Clark, 1983, p. 230) centered on "the research imperative," which "integrated research and teaching in the full professor" (Clark, 1983, p.47). After World War II, the US higher-education system was adopted by Japanese higher education; however, many Japanese national universities retained the chair (koza) model, which is focused on "both research and teaching," as a unit (Clark, 1995, p. 167).

Coleman (1999) explained the differences between the Japanese koza higher-education system and the US science departments (pp.19-25). In the US departmental system, 
professors and associate professors are independent from each other; however, in the Japanese koza system, more than one faculty member belongs to the same koza unit, and they are involved in funding, student guidance, and research.

Japanese higher-education institutions use Japanese when teaching. After the Meiji Restoration in the late $19^{\text {th }}$ century, there were discussions about using English as the language medium; however, Japanese higher-education institutions have continued to use Japanese and to translate books into Japanese, even though they send academics abroad and bring in western academics (Altbach, 2016, p.209).

\subsection{Attempts at Internationalization in Japanese Higher Education}

Since the early $21^{\text {st }}$ century, the Japanese government has taken some initiatives to attract more inbound international students and to increase the global competitiveness of Japanese higher-education institutions. After a plan was announced in 1983 to have 100,000 international students by the early $21^{\text {st }}$ century, in 2008 , the renewed goal was to increase the number of international students to 300,000 by 2020 (MEXT, 2008).

Consequently, the "G30" project was started soon after these announcements in 2008, with English-medium undergraduate programs commencing in selected universities (JSPS, 2010). As Japanese-medium courses were considered a disadvantage in attracting international students to Japan, English-medium courses became a viable alternative; however, the establishment of these courses proved to be quite challenging for the Japanese higher-education institutions involved (Ishikawa, 2011).

Another ambitious funding project called the "Top Global University Project" commenced in 2014 (MEXT, 2014) to increase the global presence of higher education in Japan and to "boost the international competitiveness of Japanese higher education overall to see more Japanese institutions among the top-ranked universities in the world." (Goodman, 2016, p. vii) These initiatives were associated with an initial five to ten years of funding to motivate the internationalization of Japanese universities.

As the number of inbound students grew at Japanese higher-education institutions, there was also increasing interest in the outbound mobility of Japanese students, which was being promoted by several initiatives, such as the "Top Global University Project." Yonezawa and Shimmi (2015) discussed the development of higher-education internationalization in Japan from a historical perspective.

\subsection{International Students in Japan}

Studies on international students in Japan have been influenced by the developments in higher education as well as the social and economic changes in Japan and around the world. Researchers have focused on the issues and problems faced by institutions when bringing in international students (Onishi, 2016; Yokota \& Shiratsuchi, 2004).

However, in addition to research on international students that has attempted to link higher-education policies and internationalization, it is also important to have micro-level longitudinal and follow-up studies (Collins, Ho, Ishikawa, Ma, 2017) to examine international-student experiences; unfortunately, there have been few long-term studies on the provision of Japanese international education.

\section{Studies on International Students and Relevant Research Approaches}

\subsection{Past Studies on International Students}

International students' concerns at higher educational institutions have always been closely related to political, economic, and social issues, as well as those of current international relations in specific countries and throughout the world. For example, in the late $20^{\text {th }}$ century, Altbach, Kelly, and Lulat (1985) reviewed and discussed various themes related to international study in conjunction with international students' literature. They discussed foreign study from a historical perspective, which reminds us of the origin of the international nature of higher education ( $p$. 3 ). In addition, they critically reviewed previous research on international students and accordingly noted various issues, which had not been examined previously, including the impact of international students, institutional policies, health, past sojourn matters, and political economy (pp. 35-47). These issues remain imperative.

Until recently, fairly extensive studies on international students and related topics such as culture adaptation have been conducted. For example, Berry's (e.g. 1997) much cited framework explained acculturation strategies of "cultural groups and their individual members, in both the dominant and non-dominant situations" (p. 9), from two aspects: first, to maintain their heritage culture and identity; and second, to retain contact with the larger society outside (pp. 9-10). Zang and Goodson (2011, p.139) reviewed relevant quantitative studies between 1990 and 2009 and examined the predictors of the psychosocial adjustment of international students in the United States. They found that the most frequent reported predictors were social support, English language proficiency, region/country of origin, length of residence in the United States, acculturation, social interaction with Americans, self-efficacy, gender, and personality. The studies that were reviewed demonstrated diverse factors, which may be related to the psychosocial adjustment of international students. 


\subsection{Research Approaches and the Framework of This Study}

Researchers have explored various issues related to international students. The research methods have varied depending on the researchers' interests and approaches. Some have tested hypotheses by employing quantitative research methods, while others have attempted to determine whether a tested hypothesis is statistically valid. However, various other research approaches have been employed in studies of international students. The author's research framework varies from research on cross-cultural psychology, or the psychological approach, which was previously noted, to ethnographic research, specializing in educational anthropology, which the author has been conducting in the past years, and which is discussed in detail in a subsequent section. Berry, Poortinga, Segall, and Dasen (2002) explained this research approach as "approaches from cultural anthropology" (pp.225-254).

In this study, the specific aspect of Indonesian students' culture learning at a Japanese higher education institution as well as the influence of their learning on their later careers as university faculty members at an Indonesian higher education institution are examined. In the analysis of the research community koza, which is explained in detail in a subsequent section, the author used Lave and Wenger's (1991, p. 29) concept of "legitimate peripheral participation" in "the sociocultural practices of the community." According to Lave and Wenger's concept, learning becomes a "situated activity" in which "learners participate in communities of practice" (1991, p. 29). Indonesian students belong in their respective communities of koza as international students. Using Lave and Wenger's concept, Indonesian students learn participating in many situated activities; learning occurs not only in their research fields but also in many practices and relationships as they engage in various kinds of sociocultural practices of the community. This study did not only examine the content of individual students' specific majors. Rather, the learning of various kinds of practices such as learning to supervise and conduct research on the koza community, while studying in Japan was explored. Furthermore, the impact of what the students learned, particularly those who became university professors, on their life after returning to Indonesia was explored in this study.

\section{Research Method: Longitudinal Ethnographic Research on Indonesian Students}

A qualitative approach is employed in ethnographic research. Furthermore, this type of research usually includes fieldwork involving an in-depth study of a community for a long period of at least one year. In addition, the researcher uses the language of the people of the community and endeavors to learn about their world. The author's fieldwork in Japan in 1991- 1992, follow-up research in Japan, and research in Indonesia in the late 1990s and 2010s is subsequently described.

\subsection{Ethnographic Fieldwork}

To clarify what happens when new international students go to a new environment, the author decided to focus on Indonesian students who study in Japan. The author studied the Indonesian language. The fieldwork was conducted at a Japanese national university (hereafter called University A) from 1991 to 1992 at which 21 Indonesian students were studying. Most were graduate engineering students and had brought their families to Japan while they completed their studies. All had received scholarships either from the Japanese government or from the Indonesian government. Furthermore, all graduate students had positions at a university or in a government department in Indonesia.

During the fieldwork, the author stayed in the city in which University A was located. She conducted intensive participant observations of four students in the first part of the study. She observed one student at a time at the laboratory of the koza in which the student was a member. After obtaining the particular student's permission, as well as that of the professor in the koza, the author went to the student's laboratory every weekday for the entire day to observe his/her activities. The activities included conducting research, discussions, and consultations with the professors and other students, chatting with other students, and having meals with other members in the cafeteria. The observation of the first participant took longer than that of the other three participants as the author has to become acquainted with their different types of activities and how they interacted with other members of the koza.

Furthermore, the author participated in participants' activities during weekends; these included attending the Indonesian student association meetings and going out with close friends. As the families of the participants arrived in Japan, the author participated in their family's activities, which included going to the city office for various procedures and to local education boards to get their children enrolled at schools.

During the latter half of the fieldwork, the author conducted interviews with other Indonesian students on selected topics, which had become important during the observations and interviews of key participants during the first part of the fieldwork.

During the fieldwork, the author kept detailed notes of her observations and interviews. These were used as the data for the analyses of the lives of Indonesian students studying at University A. The analyses were performed in accordance with the recurrent patterns and important issues that became apparent through the observations and 
interviews.

The author learned how the participants engaged in and interpreted their lives in Japan as international students studying for degrees. The importance of network and community among the Indonesian students, as well as the importance of acquiring a degree for their future career, was evident. They perceived their future to be in Indonesia. Consequently, acquiring a degree was imperative for those who were in the graduate program and for those who had positions in Indonesia.

\subsection{Follow-up Research in Japan and in Indonesia}

After the main fieldwork in 1991- 1992, the author conducted several follow-up studies at the University A between 1994 and 1997; she stayed between three days and one week each year. The author observed and interviewed participants and their families who were in the final stage of their doctoral programs.

After the key participants had completed their studies and returned to Indonesia in the late 1990s, the focus of the research shifted to Indonesia, where follow-up studies were conducted; the first was conducted in the late 1990s after they had just returned from Japan. The most recent follow-up study was conducted in early 2010, which allowed for an exploration of the longitudinal impact of graduate study in Japan ${ }^{2}$. In the follow-up studies, students who had studied at a later time in Japan and students who had studied in countries other than Japan were also interviewed to have a comparative basis on which to examine the experiences of the graduate-students.

A brief mention of follow-up studies on university faculty with doctoral degrees follows. In 2011, six returnees who had studied at University A in Japan for about 20 years previously and had faculty positions at University B in Indonesia were interviewed. In 2013, 14 returnee faculty members at University B were interviewed, nine of whom had studied in Japan (six had studied both in Japan and in other countries), four of whom had studied in other countries, and one of whom had studied in Indonesia. Recent Japanese alumni who were familiar with the more current Japanese university innovations, such as regular English-medium programs were among them. These follow-up studies have provided important findings with regard to the impact of international study and the changes that have taken place in Japanese universities.

\section{Study Context}

\subsection{Koza Research Units and the Graduate-student System at Japanese Universities}

\subsubsection{Koza Research Unit at University A}

To fully examine the international-student experiences, it is important to understand the context within which the international students studied. In this paper, the situation of the engineering graduate students at Japanese University A in the 1990s is first explained.

University A, a national university in Japan that became a national university corporation in 2004 , has a research unit called a koza in each department. Each specific koza is commonly called something like "professor X's research office (X sensei no kenkyushitsu)" or "X ken" for short in Japanese. In the koza, there is usually one head professor, associate professors, and assistant professors, and, depending on the field, there are also technical assistants. The number of faculty in each koza varied depending on the koza. Today, the systems have changed, and there are faculties and departments that have larger koza systems and more than one professor in the same koza unit. However, in the engineering and science departments, the original koza system has been retained, with only one professor and other faculty members of different ranks.

Students are also members of the koza, for which there is a hierarchy depending on the year they entered, such as graduate doctoral students, master's level students, and senior year undergraduate students, with the number of students varying from one or two to as many as twenty.

\subsubsection{Koza Teaching and Research Practices}

There were various practices and activities in each koza, with the teaching contact between the professors and the students varying depending on the koza. For example, in some koza, each student had a research topic and a specific faculty member in the koza as supervisor; however, other koza had small groups based on the research topic, with a faculty member in charge and student groups working on related topics.

In the following, as noted previously, this koza system is described using Lave and Wenger's (1991) concept of "legitimate peripheral participation" in "the sociocultural practices of the community" (Lave \& Wenger, 1991, p.29). Lave and Wenger were instrumental in changing the view of learning as a "situated activity" to something where "learners participate in communities of practice, and that the mastery of knowledge and skill requires newcomers to move toward full participation in the sociocultural practices of a community" (Lave \& Wenger, 1991, p.29).

The students in a particular koza were expected to learn from each other. The younger or junior students were assisted by the senior students in learning to conduct research and use equipment. By the time the senior students graduated, the younger students were expected to have gained the knowledge and skills necessary to become seniors and were expected to assist the new students joining the koza.

Seminars were held regularly so that students could report on their research progress and other koza members could comment, and regular meetings were held to read and discuss journal papers. The $\underline{\text { koza }}$ also conducted non-academic activities, such as welcome parties when new members joined, farewell parties when professors or senior students left, year-end parties, or one-day or 
overnight trips, in which all members were expected to participate.

Professors in the koza usually applied for and obtained funding for the students' research and experimental research, and the students could be assigned research topics that were part of the professor's research; therefore, the published research was a product of both the professor and the concerned members of the koza.

In addition to the professors' offices, each koza had rooms for the students and, depending on the field, its own experimental facilities. Students were placed in big rooms, with each student having a desk and a chair. Some koza also had free space with tables, chairs, and sofas where students could spend time together, and others had a mini kitchen with a sink, stove, and refrigerator where members could cook and eat together, as most students stayed in their koza all day and sometimes even at night.

Access to the people, resources, research methods, practices, and other activities in the koza community provided valuable learning experiences for new members, as it gave them a chance to gain knowledge and expertise through becoming involved in some of the senior student's research and experiments. Therefore, the relationships between the koza members were very important. The koza community influenced the life of both international and local students through the many academic and non-academic activities.

\subsection{Departmental System at University B in Indonesia}

Indonesian higher-education institutions had a different system from that found in Japanese universities. During colonization, the Dutch were uninterested in Indonesian higher education (Altbach, 2016/1989 p. 205); however, after independence, Indonesia discarded the Dutch system for one styled on the US education system (Altbach, pp.200-201).

University B is a national university in Indonesia that became a national corporation in 2000 . The departmental system is similar to that found in American universities, with each faculty member working independently. Student research supervision is one-to-one with a supervising professor, and each student has to pay their own research costs, which can be difficult for some students.

\subsection{Experience of the Different Research Units from International Study}

This section examines the future of the Indonesian koza graduate students to clarify the methods they had applied from their Japanese studies, to further investigate their graduate-student experiences in Japan, and to assess the influence of their international-student experience on their academic careers as faculty members who teach and supervise students in Indonesia.

\section{Indonesians Who Studied in Japan, and Reflections on Their Academic Careers in Indonesia}

The cases below describe the experiences of graduate-student Indonesians in Japan and how this influenced their teaching on their return to Indonesia, with a specific focus on their ideas and practices about supervising students and research. Pak ${ }^{3}$ Pranowo's experiences are fully described, and then specific issues are discussed by several others.

\subsection{Pak Pranowo}

Pak Pranowo graduated from the Faculty of Engineering at Indonesian University B, after which he became a lecturer in the department from which he had graduated. He obtained an Indonesian Government Scholarship and went to Japan in April 1989. After a half year of intensive Japanese language study, he became a research student at the Graduate School of Engineering at University A. Then, after passing the entrance exam for the master's program, he entered the program in April 1990. After completing the program with a master's thesis and passing the entrance exam, he entered the doctoral program in April 1992. He finished his doctoral program in October 1995, returned to Indonesia and resumed his faculty position at University B.

\subsubsection{Struggles in the koza in Japan}

Pak Pranowo was the first international student to join his particular koza. While studying in Japan, Pak Pranowo was initially engaged in several academic as well as non-academic activities in his koza community. However, as time passed, he became selective about the kinds of activities in which he participated.

Pak Pranowo was assigned to one of several small research groups in his koza. However, there were times when the group members conducted experiments for him without explaining them to him or asking him for help. Therefore, he felt that if he did not help in the research, it would be difficult for him to learn how to conduct the experiments himself.

Pak Pranowo explained that he was unable to fit easily into relationships with the other students. The senior students in the koza were usually older and would order the junior students about in their research and in other matters. However, Pak Pranowo was older in age but junior in year when he entered the koza, which made it difficult for the Japanese students to order Pak Pranowo around.

Pak Pranowo also had problems in his relationship with his direct supervisor, an associate professor, as the professor expected Pak Pranowo to become a "Japanese" doctoral student and behave in the same way as the other Japanese in the koza - that is, to concentrate on research, even if this meant staying in the koza overnight and eating instant noodles. However, Pak Pranowo had his family 
with him and therefore went to the koza during the daytime and left earlier to take care of his family. Sometimes, however, Pak Pranowo would return to the koza at night after seeing to his family.

After several years of struggles, he finally obtained his doctoral degree and completed the research journal publication conditions and other requirements.

\subsubsection{Career in Indonesia: Creating a koza System in Indonesia}

When he returned to Indonesia in 1995, Pak Pranowo had to restart after several years away from his work at University B. However, with his doctoral degree and the confidence he had gained from his years of study in Japan, he soon became very active in teaching, research, and other activities. After obtaining the necessary points in the promotion system, Pak Pranowo became a full professor in 2009.

Since returning to Indonesia, Pak Pranowo has reflected on the positive experiences he had in Japan. Pak Pranowo obtained lab space so that his students could work on experiments, a free space for the students to mingle, and even a mini kitchen, all of which were modeled after his koza in Japan, and all of which allowed the students to spend time discussing research and various matters together. Pak Pranowo also applied for a research fund, and, once he gained the funding, he assigned research topics to the students he supervised. Therefore, the research conducted under his guidance and funding also became his research.

Pak Pranowo adapted the positive experiences he gained from Japan, such as cooperative learning, but he did not adopt the less positive elements, such as the vertical relationships.

\subsection{Pak Taufik}

Pak Taufik was appointed to university faculty after finishing his undergraduate program at University B in Indonesia. He was given an opportunity to receive training for one year at University A in Japan. He was granted a Japanese Government Scholarship and went to University A in 1989. After half a year of intensive Japanese study and another half as a research student, he then entered the Graduate School of Engineering at University A in the master's program in 1990. After graduating and passing the entrance examination, he entered the doctoral program in April 1992. He finished that program in 1997, returned to Indonesia, and resumed his faculty position at University B.

\subsubsection{Koza Community Life in Japan}

Pak Taufik's koza had a different system to Pak Pranowo's. In Pak Taufik's koza, each student worked individually on their research and experiments, and each student had a supervising professor who was an associate or assistant professor. When the students needed research guidance and advice, they would ask the senior students or the professors in charge. Pak Taufik's koza had always had international students, and the members were therefore used to collaborating with students from different cultures. In addition to consulting with the professor in charge, Pak Taufik was able to consult in English with the senior students who had desks in the same room regarding his research and other matters.

His research went well in his master's program; however, in his doctoral program, he faced problems as he changed his research topic. He also became bitter because his experiments went poorly. He struggled for several years to obtain results and become published, and he finally completed his doctoral degree in 1997.

\subsubsection{Research and Guidance with Funding}

Upon his return to Indonesia, Pak Taufik was active in teaching, research, and other projects. He initiated a funding and guidance system in which the students would work on research with Pak Taufik. Every morning, he met with his students to discuss their research progress and give advice. He applied for and received research funds so that the students did not have to pay for their experiments and could concentrate on their work. Pak Taufik said that the lab work was demanding, which motivated the best students to work with him.

\subsection{Pak Dadang: Regular Meetings with Students}

Pak Dadang finished his undergraduate program in 1998 and was appointed to the university faculty at University B. He went to Japan in October 2001 on a Japanese government scholarship, and after six months of intensive Japanese language study, he entered the graduate program at University D in Japan from April 2002 and stayed until March 2007, graduating from the master's program and enrolling in the doctoral program. He obtained his doctoral degree, returned to Indonesia, and resumed his work as university faculty.

During his studies in Japan, Pak Dadang faced problems in his first year, as he was unable to communicate well in Japanese; however, he overcame these problems in his second year. He had good relationships in his koza with his professors and other students, and he gained valuable advice about his research from the senior students. Pak Dadang's koza had a rule that everyone had to present in English; therefore, Pak Dadang was able to help the other students with their English. He was the only international student when he entered his koza; however, by the time Pak Dadang entered the doctoral program, he was the most senior student in his koza, and, in addition to other Japanese students, several more international students had joined the koza at master's level. He was very active in his research, presenting in international conferences and working jointly with other researchers; he was also 
involved in many non-academic koza activities.

Upon his return to Indonesia, he actively pursued research funds. He also routinely advised students, meeting once every two weeks so that students could report on their research. He would also meet students regularly to read research papers.

\subsection{Pak Tito: Individual Guidance with a Professor in the Regular English-medium Program}

Pak Tito became a faculty member at University B, from which he had graduated in 1997. He studied for his master's degree in Singapore from 2002 to 2004; he then enrolled in the English-medium doctoral program at University E in Japan from 2009 to 2013 on a Japanese scholarship. When I interviewed him in 2013, he had recently returned to Indonesia.

Pak Tito had one associate professor in charge of his research in his koza, who met and advised him one-on-one every week. There were weekly seminars in his koza that were conducted in Japanese, and twice a year he had to report on his research; however, he only attended the seminars held in English. He talked with other students, who had similar research, but he rarely communicated with the other students in the koza; unfortunately, students in similar fields to his own were unable to speak English and those who spoke English were in different research fields. $\mathrm{He}$ generally had lunch with other Indonesian and international students from different koza.

Soon after his return to Indonesia, Pak Tito told me that the first thing he needed to do was to apply for research funding. His research space is his office.

\subsection{Pak Heri: Positive Experiences in a Regular English-medium Program Koza}

Pak Heri finished his undergraduate program in 2001. After working in companies that do business with Japan and other countries, he was appointed to university faculty in 2003. He obtained a scholarship and studied in a master's program in Malaysia, after which he received a Japanese scholarship and went to Japan for an English-medium doctoral program at University E from 2006 to 2009.

He had a supervising professor, and the guidance was conducted one-on-one every week in his koza. He used English to communicate, and the other graduate and undergraduate students in the koza helped him with his research and with translations from Japanese and English. He fondly remembered his time in Japan and the support given to him by the koza community, and he was satisfied with the home-like atmosphere.

Upon his return to Indonesia, Pak Heri started to regularly supervise his students. Once every two weeks, his students reported on their research and he advised them, and, when necessary, he assisted them with their journal papers. In addition, Pak Heri held parties for student graduations, even though this was not an experience he had had in Indonesia.

\section{Discussion}

\subsection{Graduate-student Learning in Japan}

In the koza communities that the Indonesian students joined, there were similarities in the system designs of a head professor, other professors of different ranks, and students from different years. However, each specific koza provided different experiences and learning opportunities.

Overall, studying and researching in the koza community, in which expertise and knowledge were relation-dependent, influenced the students' learning significantly; that is, in their respective koza, their learning was influenced by what they learned, with whom, and in what way. If a newcomer to the koza community had good relationships with the other members, they could learn from the senior members by assisting with the senior's research. If the students did not have good relationships or were denied access to expertise and knowledge, they faced difficulties with their learning.

Therefore, as described, the learning and research progress of international students was influenced by their relationships with the other members, the professors, and the students, as well as by the accessibility given to the knowledge, expertise, and resources in the koza.

\subsection{Impact of Graduate Study in Japan on the Academic Careers of Indonesian Professors}

Even though they studied in Japan at different times (Pak Pranowo and Pak Taufik in early 1990s, and Pak Dadang in the early 2000s), all three studied in "traditional"4 regular graduate programs at Japanese universities, and they were in their koza every day for five to six years. As recounted, their experiences in these traditional koza influenced their research, their relationships with professors and students, their ideas about collaborative research, and the use of research funds for joint professor-student research.

Pak Pranowo adapted Japanese practices that would work in his own academic career; for example, he was able to obtain a space for his students to engage in group activities. Pak Taufik also adopted the idea of collaborative research groups. They all received research funding, and all of them had students conduct research under their advice. Pak Dadang also tried to have regular research-advice meetings with students.

Their assessment of their studies in Japan and how they applied the lessons they learned to the Indonesian context demonstrated the influence of their graduate studies in Japan, as most of the practices were unfamiliar to universities in Indonesia. 


\subsection{Increase in English-medium Programs at Japanese Universities}

English courses and English-language programs are increasing in Japanese universities. As in the traditional koza, the Indonesian student cases in the English-medium programs illustrated the impact that the koza had had. The respective koza communities influenced the lives of each student differently, and they demonstrated that regardless of language, the learning in the koza had significantly influenced their subsequent careers.

These Indonesian Japanese alumni cases show the importance of understanding the specific contexts for international students studying in a koza community. Even in the English-medium programs, there were koza communities that continued to use Japanese, as exemplified by Pak Tito, resulting in less substantial relationships. However, Pak Heri, who was also part of an English-medium program, had positive experiences with his koza community.

Regardless of language use, if international students had good relationships with the other koza members and were able to get access to the koza knowledge and expertise, they could learn from their experiences and activities. On the other hand, if they did not have good relationships or if access was limited, then their learning was also limited. Although Pak Tito may have learned about his research from his supervisor, he did not have the chance to learn about other practices or develop the types of relationships that were experienced by Pak Heri and the others.

These findings highlight the importance of examining specific international-student study contexts. For these Indonesian graduate students, who studied in Japan, the specific koza community they belonged to influenced their respective experiences and learning, which then influenced their teaching and research practices in their subsequent academic careers in Indonesia. However, these returnees did not copy the practices they learned in Japan; instead, they adapted the practices that they valued and modified them to suit the teaching and research environment in Indonesia.

\section{Summary and Conclusions}

This paper examined the impact of international study from international students' perspectives, with a specific focus on koza communities in Japanese higher-education institutions. The research was based on a longitudinal ethnographic study on Indonesian graduate students who had studied in Japan in order to examine the long-term influence on their subsequent academic careers in Indonesia. It was found that several alumni selectively chose teaching and student-advice practices that they had positively valued from their respective Japanese koza to adapt in their later academic careers.

This research has made a contribution to the study of international students who experience different educational systems. Employing Lave and Wenger's (1991) concept of situated learning in "sociocultural practices of the community," long-term impact of culture learning of Indonesian students at Japanese universities who pursued academic careers as university professors in Indonesia was clarified. In international-student studies, it is important to examine both the macro and the micro levels to fully understand the long-term influence of the international-student experience. More micro-level longitudinal studies are needed as an increasing number of universities internationalize and international student-mobility increases.

\section{Notes}

This manuscript is based on the author's original research and publication in Japanese (Author, 2016).

1. Altbach (2016) includes the chapters that he published in the past years. In this paper, the year of the original publication is also included in parentheses after "/" in the first reference. The page numbers cited are from Altbach (2016).

2. These follow-up studies were supported by JSPS KAKENHI Grant Number JP23402062.

3. "Pak" is added before a man's name in formal reference in the Indonesian language.

4. This is used in contrast to the English-medium program.

\section{Acknowledgements}

The author would like to thank Enago (www.enago.jp) for the English language review.

\section{REFERENCES}

[1] Altbach, P. G., 2016, Global perspectives on higher education, Baltimore, Maryland: Johns Hopkins University Press.

[2] Altbach, P. G., 1989, twisted roots: The Western impact on Asian higher education. Higher Education, 18, 9-29.

[3] Altbach, P. G., Kelly, D. H., \& Lulat, Y. G-M., 1985, Research on foreign students and international study: An overview and bibliography. New York: Praeger.

[4] Author, 2016, Nihon ryugaku no esunogurafi (Ethnography of study in Japan), X University Press.

[5] Berry, J. W. 1997, Immigration, Acculturation, and Adaptation, in Applied Psychology: An International Review, 46(1), 5-68.

[6] Berry, J. W., Poortinga, Y. H., Segall, M. H., \& Dasen, P. R., 2002, Cross-cultural psychology: Research and applications (Second Ed.), Cambridge, UK: Cambridge 
University Press.

[7] Clark, B. R. 1983, the higher education system: Academic organization in cross-national perspective. Berkeley \& Los Angeles, CA: University of California Press.

[8] Clark, B. R. 1995, Places of inquiry: Research and advanced education in modern universities. Berkeley \& Los Angeles, CA: University of California Press.

[9] Coleman, S. 1999, Japanese science: from the inside, London: Routledge.

[10] Collins, F. L., Ho, K. C., Ishikawa, M. \& Ma, A. S., 2017, International student mobility and after-study lives: the portability and prospects of overseas education in Asia. Population, Space and Place, 2017; 23:e2029. DOI: 10.1002/psp.2029

[11] Goodman, R. 2016, Foreword, in Mock, J., Kawamura, H., \& Naganuma, N. (Eds.), The impact of internationalization on Japanese higher education. Rotterdam, the Netherlands: Sense Publishers.

[12] Ishikawa, M. 2011, Redefining internationalization in higher education: Global 30 and the making of global universities in Japan, Wills, D. B. \& Rappleye, J. Eds., Reimagining Japanese education: borders, transfers, circulations, and the comparative, London: Symposium Books, Ltd.

[13] JSPS (Japan society for the promotion of Sciences), 2010, Project for Establishing University Network for Internationalization (Global 30). Tokyo: JSPS. http://www.jsps.go.jp/english/e-kokusaika/index.html Accessed November 5, 2017.

[14] Lave, Jean, \& Wenger, Etienne, 1991, situated learning: Legitimate peripheral participation, Cambridge: Cambridge University Press.

[15] MEXT, 2008, "Ryugakusei 30 man nin keikaku" kosshi no sakutei ni tsuite (Development of Outline of "Plan of 300,000 international students"). Tokyo: MEXT [in Japanese]. http://www.mext.go.jp/b_menu/houdou/20/07/0 8080109.htm Accessed November 5, 2017.

[16] MEXT, 2014, Supa gurobaru daigaku sousei shien jigyou (Top Global University Project) [in Japanese] http://www.mext.go.jp/a_menu/koutou/kaikaku/sekaitenka i/1360288.htm English site https://tgu.mext.go.jp/en/index. html Accessed November 5, 2017.

[17] Onishi, A. 2016, Kyanpasu no kokusaika to ryugakusei soudan: tayousei ni taioushita gakusei shien sabisu no kochiku (Internationalizing campus and consulting of international students: Constructing student support services meeting the needs of diversification). Tokyo: Tokyo University Press.

[18] Yokota, M. \& Shiratsuchi, S. 2004, Ryugakusei adobaijingu: gakushu seikatsu shinri wo ikani shien suruka (Advising of international students: How to support their study, life, and psychology). Tokyo: Nakanishiya.

[19] Yonezawa, A. \& Shimmi, Y., 2015, Transformation of university governance through internationalization: challenges for top universities and government policies in Japan, Higher Education, Vol. 70, pp.173-186.

[20] Zang, J. \& Goodson, P. 2011, Predictors of international students' psychosocial adjustment to life in the United States: A systematic review, in International Journal of Intercultural Relations, 35, 139-162. 